\title{
Molecular Dynamics of The Early Stages of High Temperature Corrosion
}

\section{Sung-Yup Kim ( $\square$ kim.7715@osu.edu )}

OSU: The Ohio State University https://orcid.org/0000-0001-6987-2323

\section{Christopher D. Taylor}

The Ohio State University

\section{Research article}

Keywords: high temperature corrosion, reactive force field, molecular dynamics

Posted Date: August 4th, 2021

DOl: https://doi.org/10.21203/rs.3.rs-712265/v1

License: (9) This work is licensed under a Creative Commons Attribution 4.0 International License. Read Full License

Version of Record: A version of this preprint was published at Physical Review Materials on November 17th, 2021. See the published version at https://doi.org/10.1103/PhysRevMaterials.5.113402. 


\section{Abstract}

We performed molecular dynamics simulations of the high temperature oxidation of metal alloys composed of $\mathrm{Al}, \mathrm{Cr}$ and $\mathrm{Fe}$ and compared their behavior with that of pure Fe. The metal alloy elements (Al and $\mathrm{Cr}$ ) segregated to the surface during oxidation producing a lower stress gradient at the metal/environment interface compared to pure Fe. We have found that the lowered stress gradients produced in the alloy material appear to play a key role in the development of corrosion. Interfaces with lower stress gradients have reduced rates of $\mathrm{H}_{2} \mathrm{O}$ adsorption, especially for the ferritic (bcc) alloys. The diffusivity of oxygen and hydrogen drops more rapidly for the interfaces with reduced stress gradients. The stress gradient is also diminished when the gas pressure is increased, indicating that the Fe-Cr-Al alloy system is more resistant to oxidation than pure Fe at higher pressures. Therefore, we conclude that the lower stress gradients at the alloy/environment interface reduce the stress concentration and can slow down the rate of the initial oxide scale growth. We also compared bcc and fcc alloys with pure Fe based on our 3 evaluation criteria (peak stress, stress gradient and summation of stress in the oxide scale). We found that the alloys have lower values under the three criteria compared to pure Fe. The bcc alloy has the best score under a water rich environment and the fcc alloy is proven to be the better for peak stress and summation of stress in the oxide scale under an oxygen rich environment. For surface segregation to occur, we find that a minimum content of $\mathrm{Al}$ or $\mathrm{Cr}$ content in the near-surface region must be achieved.

\section{Introduction}

Metals and alloys react with the surrounding environment during high temperature service, resulting in high temperature corrosion. High temperature corrosion reactions initiate by molecular adsorption of exhaust gases on to the material surface. Depending on the alloying elements present in the surface and near-surface region, certain reactions and adsorption processes will be favored. Following molecular adsorption, an incipient oxide scale is formed, and, once the competing surface chemistry resolves to establish the most favored corrosion product at the nanometer scale, the film will then grow due to mass transport and continual reaction of the scale surface with the environment. Once the film reaches a certain thickness, the rate of this process depends on the defect transport kinetics (interstitials and/or vacancies), and the transport kinetics will be affected by the crystal structure, microstructural aspects (e.g. oxide grain size or amorphous characteristics) and composition of the corrosion product ${ }^{1,2}$.

Mechanical effects can also influence the evolution of corrosion. Thermal expansion and lattice mismatch can result in strains within the oxide and at the oxide/metal interface, and these effects can lead to cracking and spallation, especially as the oxide film grows thicker ${ }^{3}$. In the early stages of film formation, however, the controlling processes and effects are not as well known, due to the inability to capture the composition and geometry of very early stage films experimentally (atoms to nanometers). High temperature corrosion is a complex multiphysics and multiscale phenomenon which involves the intersection of thermodynamic stability, chemical reaction kinetics, molecular diffusion and mechanical properties, etc. 
Among the many applications of high temperature corrosion, we are interested in automotive exhaust manifold components. Alloys have been actively pursued as an effective way to improve cycle efficiency and durability by mitigating corrosion and oxidation. Having a thin, stable, yet sufficiently passive, oxide layer is particularly important, since the mechanical stability of the surface oxide layer that forms on the alloy can be just as critical to performance as the bulk alloy properties. Due to thermal cycling, and abrasion forces from particles in the exhaust, the oxide films may break, exposing the 'raw' alloy surface, and resulting in further corrosion product formation. It is therefore important to consider how alloy design chemistry can be controlled to favor the formation of a more highly adherent, thin, and mechanically stable oxide films on the alloy surface. In our current study, we focus on developing a methodology for studying the early stages of oxidation in a model Fe/Al/Cr alloy ternary system, as it is known that favorable high temperature corrosion resistance is conferred by the co-presence of chromia and alumina scales.

Reginal et al. ${ }^{4,5}$ found that aluminum and chromium additions to steel help form and maintain a protective oxide layer, and critical alloying contents were required to prevent passive layer breakdown. Wang et al. ${ }^{6}$ confirmed, using DFT (density functional theory) calculation and experiment, that $\mathrm{Cr}$ as well as Al content play an important role in the oxidation resistance of $\mathrm{Fe}-\mathrm{Al}-\mathrm{Cr}$ alloys at high temperature. They found that $\mathrm{Cr}$ atoms diffuse at the $\mathrm{Fe} / \mathrm{Al}_{2} \mathrm{O}_{3}$ interface under high temperatures, replacing some of the $\mathrm{Al}$ atoms in $\mathrm{Al}_{2} \mathrm{O}_{3}$, thus forming composite oxides $\left(\mathrm{Al}_{\mathrm{x}} \mathrm{Cr}_{1-\mathrm{x}}\right)_{2} \mathrm{O}_{3}$ in the lower oxide layer resulting in subsequent formation of multi-oxide layers. They determined that the presence of $\mathrm{Cr}$ in $\mathrm{Fe} / \mathrm{Al}_{2} \mathrm{O}_{3}$ increases the interfacial bonding energy. Nurmi et al. ${ }^{7}$ found by ab initio calculation that moderate $\mathrm{Cr}$ addition to Al containing steels improve ductility significantly. Since Al addition to Fe results in the deterioration of the mechanical properties, this problem can be solved by adding a suitable amount of a third alloying component, in this case, chromium. Liu et al. ${ }^{8}$ noted that addition of a small amount of aluminum (atomic $2 \%$ ) to the ternary alloy $\mathrm{Fe}-19 \mathrm{Ni}-13 \mathrm{Cr}$ did not improve the corrosion resistance, while the addition of $6 \% \mathrm{Al}$ to this alloy produced a significant decrease of the corrosion rate. Airiskallio et al. ${ }^{9}$ found that substituting $\mathrm{Fe}$ by $\mathrm{Cr}$ in $\mathrm{Fe}-\mathrm{Al}$ alloys clearly increases the driving force of Al to diffuse from the bulk to the surface producing a more corrosion resistant alloy. Chen et al. ${ }^{10}$ showed that thermal cycling can result in relatively higher corrosion rates compared with isothermal conditions, which might be connected closely to the thermal stress response of the $\mathrm{Fe} / \mathrm{Al} / \mathrm{Cr}$ alloy. Beside reaction with molecular oxygen, water vapor can also react with the metal surface, and the presence of water is therefore very influential for high temperature corrosion. Understanding the role of hydrogen and its diffusion behavior into the metal and the scale is thus particularly important. Hirata et al. ${ }^{11}$ investigated the diffusion of hydrogen in bcc, fcc and hcp iron by means of first principles calculations and found that the diffusion energy barrier is lowest for the bcc structure.

Despite this prior work, there remains a need to develop a multi-physics model for the coupling between mechanical and chemical phenomena. The evolution in chemical composition and mechanical properties of the oxide scales forming during oxidation and corrosion is a grand challenge for the corrosion research 
community. In the current study, we have applied molecular dynamics to simulate the early stages of alloy oxidation.

The main objective of this work is to understand what factors control the process of high temperature oxidation in the early stage from a mechanical and chemical point of view. A number of molecular dynamics simulations ${ }^{12-18}$ of corrosion behavior have been reported for systems such as nickel, iron, aluminium and zirconium ${ }^{1}$. Here, state-of-the-art ReaxFF ${ }^{19}$ reactive molecular dynamics simulations, that can take into account not only changes in local geometry of atoms but also changes in the oxidation state, have been performed to tackle these issues. We used reactive force field (ReaxFF) parameters for $\mathrm{Al}-\mathrm{Cr}-\mathrm{Fe}-\mathrm{H}-\mathrm{O}$ materials to simulate the corrosion process of alloys composed of $\mathrm{Al}, \mathrm{Cr}$ and $\mathrm{Fe}$. The corrosion behavior was compared to that of pure, ferritic (bcc) Fe. $\mathrm{H}_{2} \mathrm{O}$ and $\mathrm{O}_{2}$ were used as the surrounding gases. $\mathrm{CO}$ and $\mathrm{CO}_{2}$ are also important exhaust gases, but in our early testing, we determined that the ReaxFF parameter between $\mathrm{C}$ and the metal elements, particularly $\mathrm{Al}$, needs to be further improved. For this reason, only $\mathrm{H}_{2} \mathrm{O}$ and $\mathrm{O}_{2}$ were considered as the surrounding gases in this work. Furthermore, the $\mathrm{CO}_{2}$ partial pressure is expected to only have a mild and possibly inhibiting effect on the alloy corrosion, compared to the effects of oxygen and water vapor ${ }^{2}$. With reactive dynamics simulations, we were able to simultaneously track and correlate the oxidation rate, stress distributions and evolution of oxide scale. We found that the alloyed material has advantages over pure Fe mechanically and chemically, because the alloy effectively reduces the extent of local stress concentration in the oxide scale and suppresses the oxide scale growth. Furthermore, the effect of alloying elements, alloy composition, temperature, pressure and gas compositions on the corrosion behavior of alloys and pure Fe were studied. The insights and approach developed through this work should lead to new approaches for predicting and tailoring the surface segregation of the elements within alloys for an improved understanding of design for corrosion resistance that recognizes the interplay of chemical and mechanical behaviors during corrosion.

\section{Al/cr/fe Alloy And Pure Fe Corrosion Simulation Details}

By using the $\mathrm{Al} / \mathrm{Cr} / \mathrm{Fe} / \mathrm{H} / \mathrm{O}$ ReaxFF parameterization developed by Shin et al. ${ }^{20}$, reactive MD simulations were performed on the metal alloy and pure $\mathrm{Fe}$ with $\mathrm{H}_{2} \mathrm{O}$ and $\mathrm{O}_{2}$ to compare corrosion behaviors of alloys and pure Fe. The alloys were composed of $\mathrm{Al}, \mathrm{Cr}$ and $\mathrm{Fe}$. We simulated alloys with different composition ratios to investigate how $\mathrm{Al}$ or $\mathrm{Cr}$ affected the high temperature corrosion performance of the alloy compared to pure Fe. In this study, 1) $50 \% \mathrm{Fe} ; 25 \% \mathrm{Al} ; 25 \% \mathrm{Cr}$, 2) $70 \% \mathrm{Fe} ; 25 \% \mathrm{Al} ; 5 \% \mathrm{Cr}$, and 3) $70 \% \mathrm{Fe}$; $25 \% \mathrm{Cr} ; 5 \% \mathrm{Al}$ were used for the alloy composition. 
Table 1

Alloy composition in terms of atomic percent and weight percent.

\begin{tabular}{|llll|}
\hline Alloy notations & $\begin{array}{l}\text { (Bcc: Alloy B1, } \\
\text { Fcc: Alloy F1) }\end{array}$ & $\begin{array}{l}\text { (Bcc: Alloy B2, } \\
\text { Fcc: Alloy F2) }\end{array}$ & $\begin{array}{l}\text { (Bcc: Alloy B3, } \\
\text { Fcc: Alloy F3) }\end{array}$ \\
\hline Atomic percent & $50 \% \mathrm{Fe} ; 25 \% \mathrm{Al} ; 25 \% \mathrm{Cr}$ & $75 \% \mathrm{Fe} ; 20 \% \mathrm{Al} ; 5 \% \mathrm{Cr}$ & $75 \% \mathrm{Fe} ; 20 \% \mathrm{Cr} ; 5 \% \mathrm{Al}$ \\
\hline Weight percent & $59 \% \mathrm{Fe} ; 14 \% \mathrm{Al} ; 27 \% \mathrm{Cr}$ & $84 \% \mathrm{Fe} ; 11 \% \mathrm{Al} ; 5 \% \mathrm{Cr}$ & $78 \% \mathrm{Fe} ; 19 \% \mathrm{Cr} ; 3 \% \mathrm{Al}$ \\
\hline
\end{tabular}

Table 1 shows alloy notations, the atomic percent of the elements in the alloy and the corresponding weight percent used in this study. Due to the constraint on system sizes in molecular dynamics simulations, it should be considered that the compositions probed reflect only near-surface compositions (i.e. 10 s of nms from the surface) rather than bulk compositions. Hence, our work provides insight to what processes may be occurring on alloy surfaces that have compositions which may already have some level of near-surface variation from the bulk chemistry due to natural enrichment as a consequence of the manufacturing and ageing processes. This kind of scenario may be relevant in situations such as corrosion fatigue, for example, when a crack surface opens up fresh material, or in the spallation of an oxide film, to expose fresh metal surface that then reacts with the incoming exhaust gases.

Once the metal structures were constructed, a mixture of $\mathrm{H}_{2} \mathrm{O}$ and $\mathrm{O}_{2}$ molecules was placed into the supercell alongside a slab of either alloy or pure Fe (Fig. 1). To avoid liquid-like densities and high pressures, the initial total number of $\mathrm{H}_{2} \mathrm{O}$ and $\mathrm{O}_{2}$ was restricted to 200 and another set of $\mathrm{H}_{2} \mathrm{O}$ and $\mathrm{O}_{2}$ molecules was introduced into the simulation box as a surrounding gas every 500 ps after the adsorption of initial $\mathrm{H}_{2} \mathrm{O}$ and $\mathrm{O}_{2}$ to metal structures (to simulate a fresh flux of oxidizing gases). Replenishing the gas molecules every 500 ps causes spikes of number of $\mathrm{H}_{2} \mathrm{O}$ and $\mathrm{O}_{2}$ every 500 ps. (Fig. 2), while this does not cause any spikes in the metal element distribution.

To see the relative effect of $\mathrm{H}_{2} \mathrm{O}$ and $\mathrm{O}_{2}$ content on the corrosion of the metal and alloy surfaces, two different $\mathrm{H}_{2} \mathrm{O}: \mathrm{O}_{2}$ number ratios were used (1:3 and 3:1). Bcc and fcc alloys were prepared to investigate the structure effect on the high-temperature corrosion (i.e. ferritic vs austenitic steels). The alloys were made through Large-scale Atomic/Molecular Massively Parallel Simulator (LAMMPS) package ${ }^{21}$. Initially the Fe element was distributed at lattice sites for the metal alloy (100) orientation and then Fe atoms were randomly replaced with $\mathrm{Al}$ or $\mathrm{Cr}$ to achieve the desired ratio of $\mathrm{Al}$ or $\mathrm{Cr}$. That is, a homogeneous random distribution of $\mathrm{Fe}, \mathrm{Al}$ and $\mathrm{Cr}$ was made. The slab thickness is $27.3 \AA$. The slab thickness does not play a role due to the limited amount of oxidation that can be achieved within the molecular dynamics time scales. During the simulation, the metal alloy atoms are free to move off the lattice sites and may transform into other phases during oxidation and the metallic layers sometimes can become amorphous near the surface. Although such phase transformation may happen during the oxidation process, the present focus of research is on the chemical reactivity to form and grow the oxides. That is, we consider such effects within the alloy to be a perturbation upon the chemical kinetics, rather than the main controlling factor. These perturbations may be studied in future work. 
Energy minimizations were performed for the structures surrounded by $\mathrm{H}_{2} \mathrm{O}$ or $\mathrm{O}_{2}$ until the energy tolerance of $10^{-5} \mathrm{eV}$ was satisfied. MD simulations were then carried out in the canonical ensemble $(\mathrm{NVT})$ at the temperature of $800 \mathrm{~K}\left(527^{\circ} \mathrm{C}\right)$ using the velocity Verlet algorithm with a time step of $0.5 \mathrm{fs}$. This temperature is somewhat lower than the typical exhaust gas temperatures, which may vary between $\sim 700^{\circ} \mathrm{C}$ to $\sim 1100^{\circ} \mathrm{C}^{22}$. Two-dimensional slab models were used for the simulations and the box size was $28 \AA ̊ 28 \AA \circ \times 100 \AA$. The forces were computed using the ReaxFF ${ }^{19}$, as implemented in the Large-scale Atomic/Molecular Massively Parallel Simulator (LAMMPS) package ${ }^{21,23}$. For the analysis of MD results, we divided the simulation box along the $z$-direction and divided the atoms into bins of width $1 \AA$. We then computed the mean value of the atomically resolved stress at each bin to investigate the elemental and stress distributions in the oxide scale. (Fig. 1(b))

\section{Reactive Force Field}

The reactive force-field (ReaxFF) interatomic potential is a powerful computational tool for exploring, developing and optimizing material properties. The ReaxFF method was developed to help bridge the gap between quantum mechanics (QM) and empirical interatomic potentials. Quantum mechanics (QM) calculations are too computationally intensive to run meaningful molecular dynamics simulations beyond a timescale of picoseconds. Alternatively, empirical interatomic potentials that are based on classical principles require a predefined connectivity between atoms, precluding simulations that involve reactive events such as bond-breaking, bond-making and changes in oxidation state. ReaxFF casts the empirical interatomic potential within a bond-order formalism, thus describing chemical bonding without expensive QM calculations. In terms of accuracy, ReaxFF retain a similar performance as QM, through fitting closely to quantum mechanical data for a variety of chemical and materials configurations for the atoms of interest.

In the ReaxFF method, the energies and forces are derived from a general energy expression:

1

The partial contributions in Eq. (1) include bond energies ( ), energy to penalize over-coordination (
) and stabilize under-coordination of atoms ( ), lone-pair energies ( ), valence angle energies ( ) and terms to handle non-bonded Coulomb ( ) and van der Waals ( ) interaction energies. All terms except the last two include bond-order dependence and depend on the local environment of each atom. The Coulomb energy ( ) of the system is calculated using a geometry dependent charge distribution determined using the electronegativty equalization method (EEM ${ }^{24}$ ). All other non-bonded interactions (short-range Pauli repulsion and long-range dispersion) are included in the van der Waals term ( ). The non-bonded interactions ( and ) are screened by a taper function and shielded to avoid excessive repulsion at short distances. For a more detailed description of the ReaxFF method, see van Duin et al. ${ }^{19}$, van Duin and Larter ${ }^{25}$ and Chenoweth et al. ${ }^{26}$. 
Note that ReaxFF does not directly have terms related to magnetism. However, since the ReaxFF force field development is based on DFT data which does account for magnetism, some magnetic effect is reflected in ReaxFF indirectly.

\section{Results And Discussion}

\subsection{Influence of oxidation \& composition on stress states at the interface and the effect of interfacial stress gradient on adsorption of water}

Figure 2. Temporal variations of mean stress profiles from pre-oxidation ( $0 \sim 0.5 \mathrm{~ns})$ to early stage oxide film formation (1.5 $2.0 \mathrm{~ns}$ ) for (a)bcc, (b)fcc alloys and (c)pure Fe. Each alloy near-surface region is set to $50 \% \mathrm{Fe}, 25 \% \mathrm{Al}$ and $25 \% \mathrm{Cr}$ in the initial condition (Table I) and the orientation of all structures is the (100) surface. $\mathrm{H}_{2} \mathrm{O}$ and $\mathrm{O}_{2}$ adsorption and reaction on alloy surfaces are monitored pre-oxidation and then after the formation of the initial oxide film on alloy surfaces compared to pure iron. The evolution of the number of free $\mathrm{H}_{2} \mathrm{O}$ and $\mathrm{O}_{2}$ molecules in the simulation cells with time is shown for (d)Alloy $\mathrm{B} 1(0 \sim 20$ ps), (e) Alloy F1(0 20 ps), (f)pure Fe (0 20 ps), (g)Alloy B1(1.5 1.65 ns), (h)Alloy F1(1.5 1.65 ns) and (i)pure Fe (1.5 $1.65 \mathrm{~ns})$,respectively. The exhaust gases consist of $\mathrm{O}_{2}$ and $\mathrm{H}_{2} \mathrm{O}\left(\mathrm{O}_{2}: \mathrm{H}_{2} \mathrm{O}=1: 3\right)$. The temperature is $800 \mathrm{~K}\left(527^{\circ} \mathrm{C}\right)$, i.e. the lower bound on exhaust gas temperatures.

1

where the , and are the normal stresses, and the , , and are the shear stresses in an $x-y-z$ coordinate system. Each alloy near-surface region is set to $50 \% \mathrm{Fe}, 25 \% \mathrm{Al}$ and $25 \% \mathrm{Cr}$. These surfaces are exposed to exhaust gas like environments composed of $\mathrm{O}_{2}$ and $\mathrm{H}_{2} \mathrm{O}$ at $800 \mathrm{~K}\left(527^{\circ} \mathrm{C}\right)$. The ratio of $\mathrm{O}_{2}$ to $\mathrm{H}_{2} \mathrm{O}$ is $3: 1$. As is shown in Fig. 2, at the initial stage of time (pre-oxidation, $0-0.5 \mathrm{~ns}$ ), all the materials/environment interfaces (for bcc, fcc alloys and pure Fe) have a steep/vertical stress gradient (> $0.6 \mathrm{GPa} / \AA$ ) at the edges. Following the formation of an initial oxide film (from 1.5-2ns), an oxide scale grows on all of the materials studied, but one distinguished behavior is observed: The Alloy B1 has a relatively gradual stress gradient across the early stage oxide scale, while the fcc alloy and Fe maintain their initial, steep stress gradients at the interface. This difference arises due to the segregation of $\mathrm{Al}$ and $\mathrm{Cr}$ in the outermost part of the oxide scale of the alloy B1 during the oxidation process (Fig. 3).

Evaluations have been made of these three materials in terms of their peak stresses, stress gradient and summation of stresses in the oxide scales. (Table 2). 
Table 2

Peak stresses and stress gradients at the surface of the oxide scales, and summation of stresses in the oxide scales for the three structures during $1.5 \sim 2 \mathrm{~ns}\left(\mathrm{O}_{2}: \mathrm{H}_{2} \mathrm{O}=1: 3,800 \mathrm{~K}\right)$

\begin{tabular}{|llll|}
\hline Metal & Peak stresses & Stress gradient & Summation of stresses \\
\hline Alloy B1 & $3.5 \mathrm{GPa}$ & $0.27 \mathrm{GPa} / \AA$ & $80.6 \mathrm{GPa}$ \\
\hline Alloy F1 & $5.1 \mathrm{GPa}$ & $0.63 \mathrm{GPa} / \AA$ & $95.6 \mathrm{GPa}$ \\
\hline Fe & $5.7 \mathrm{GPa}$ & $1.10 \mathrm{GPa} / \AA$ & $148.5 \mathrm{GPa}$ \\
\hline
\end{tabular}

According to these three evaluation criteria, the bcc alloy has the lowest values and Fe has the highest ones. Thus, the bcc alloy is the most resistant to oxidation in a $\mathrm{H}_{2} \mathrm{O}$ rich environment at $800 \mathrm{~K}$ in the very early stage of oxidation up to $2 \mathrm{~ns}$. Fe has the lowest ranking for all the criteria. Figure $2(\mathrm{~d} \sim \mathrm{i})$ shows the variation in the number of $\mathrm{H}_{2} \mathrm{O}$ and $\mathrm{O}_{2}$ molecules with time for $0-20 \mathrm{ps}(\mathrm{d} \sim \mathrm{f})$ and $1.5-1.65 \mathrm{~ns}(\mathrm{~g} \sim \mathrm{i})$, respectively for bcc (Alloy B1), fcc alloy (Alloy F1) and pure Fe, respectively. The initial number of $\mathrm{H}_{2} \mathrm{O}$ is 150 , and 50 is used for the initial $\mathrm{O}_{2}$ number. At the very initial stage of time $(0-20 \mathrm{ps})$, the numbers of $\mathrm{H}_{2} \mathrm{O}$ and $\mathrm{O}_{2}$ molecules drop very sharply, which means both $\mathrm{H}_{2} \mathrm{O}$ and $\mathrm{O}_{2}$ adsorb and react on the bare metal surface very quickly. However, for the later time period (1.5-1.65 ns), quite different behaviors are observed. The rate of $\mathrm{H}_{2} \mathrm{O}$ reaction slows down. The reaction rate of $\mathrm{H}_{2} \mathrm{O}$ is lowest for the bcc alloy followed by fcc alloy and pure Fe, which is the same order of the stress gradients produced at the interface (Table I). The lower stress gradient at the metal surface effectively means that the surface atoms are less reactive (i.e. in a lower energy state) and so they are less likely to adsorb and react with $\mathrm{H}_{2} \mathrm{O}$. On the other hand, a sharp stress gradient at the interface means that the surface atoms are in a higher energy state, and so can react with and adsorb $\mathrm{H}_{2} \mathrm{O}$ more easily. In other words, a sharp stress gradient surface is indicative of higher energy states and therefore implies a more activated surface. On the other hand, we do not find that the stress gradient has such a pronounced effect on $\mathrm{O}_{2}$ adsorption. We interpret this phenomenon to the significantly higher driving force for $\mathrm{O}_{2}$ dissociation compared to $\mathrm{H}_{2} \mathrm{O}$, meaning that the dissociation of water will be more sensitive to mechanical vs chemical effects.

The relative extent of $\mathrm{H}_{2} \mathrm{O}$ reaction does not just depend on the stress gradient at the surface. For pure $\mathrm{Fe}$, $\mathrm{H}_{2} \mathrm{O}$ preferentially reacts compared to $\mathrm{O}_{2}$. This results in Fe forming a more hydroxylated surface scale rather than a simple oxide ${ }^{28,29}$. Hydrogen atoms may diffuse through the scale to reside in interstitial subsurface sites. Further effects of stress gradient under different conditions of pressure and temperature related to $\mathrm{H}_{2} \mathrm{O}$ adsorption and alloy composition are presented in Figure $\mathrm{S} 1$ and $\mathrm{S} 2$ of Supporting Information, respectively.

Figure 3(a) shows the elemental distributions of the bcc alloy during oxidation. Surface segregation of Al and $\mathrm{Cr}$ is detected. The outermost element is $\mathrm{Al}$, followed by $\mathrm{Cr}$ and $\mathrm{Fe}$. When $\mathrm{Al}, \mathrm{Cr}$ and $\mathrm{Fe}$ are oxidized, $\mathrm{Al}_{\mathrm{x}} \mathrm{O}_{\mathrm{y}}, \mathrm{Cr}_{\mathrm{x}} \mathrm{O}_{\mathrm{y}}$ and $\mathrm{Fe}_{\mathrm{x}} \mathrm{O}_{\mathrm{y}}$ are made. Among these various oxidized structures, the most common species expected to form from thermodynamic arguments are $\mathrm{Al}_{2} \mathrm{O}_{3}, \mathrm{Cr}_{2} \mathrm{O}_{3}$ and $\mathrm{Fe}_{2} \mathrm{O}_{3}$, respectively ${ }^{30}$. This 
observation is consistent with the heat of formation order $\left(\mathrm{Al}_{2} \mathrm{O}_{3}, \mathrm{Cr}_{2} \mathrm{O}_{3}\right.$ and $\left.\mathrm{Fe}_{2} \mathrm{O}_{3}\right)$. Also, the Young's modulus of $\mathrm{Al}_{2} \mathrm{O}_{3}$ is highest followed by $\mathrm{Cr}_{2} \mathrm{O}_{3}$ and $\mathrm{Fe}_{2} \mathrm{O}_{3}$. Therefore, the modulus gradient layering in the oxide scale appears to prompt the reduction in the stress concentration ${ }^{31,32}$. Figure $3(\mathrm{~b})$ also shows that the outer stress profile is aligned with the oxygen distribution and that hydrogen sorption contributes to the inner portion of the stress profile (i.e. the metal-facing side of the nascent oxide scale). Figure 3(c) shows the Fe distribution during oxidation for the pure Fe case. A very sharp gradient of Fe is found at the interface, which is correlated with the sudden increase of the oxygen distribution profile and the sharp, steep stress gradient (Fig. 3(d)). The stress profile at the materials/environment interface is aligned again with the oxygen distribution, and the hydrogen sorption contributes to the increase of stress gradient at the the metal/oxide interface. Compared to the bcc alloy, more hydrogen is found to diffuse into the oxide scale for pure $\mathrm{Fe}$, which suggest that $\mathrm{H}_{2} \mathrm{O}$ adsorption happens easily and can diffuse fast in the earlystage oxide scale of pure Fe. Figure 3(e) compares oxygen distribution in oxide scales between bcc alloy and pure Fe. The oxygen concentration for pure Fe is higher than for the bcc alloy. For the bcc alloy, both $\mathrm{Al}$ and $\mathrm{Cr}$ segregate to the surface region, forming a protective passive layer, through which significantly smaller amounts of oxygen can penetrate into the alloy compared to pure Fe. ${ }^{33}$ Phenomenologically, it is known that surface segregation is responsible for the formation of passive films in iron-based alloys. Even a relatively small concentration of solute atoms in the alloy can lead to significant coverage of these atoms on a free surface of the alloy due to enrichment in the near-surface region. In this context, passivity is achieved through favorable surface segregation of the more thermodynamically stable oxides as a compact film with fewer stresses at the material/environment interface. ${ }^{33}$

Oxygen in the scale that originates from $\mathrm{H}_{2} \mathrm{O}$ and oxygen that originates from molecular $\mathrm{O}_{2}$ reaction with the materials are distinguished and quantified as presented in Table 3.

Table 3

Oxygen ratio between $\mathrm{O}\left(\mathrm{H}_{2} \mathrm{O}\right)$ and

$\mathrm{O}\left(\mathrm{O}_{2}\right)$

\begin{tabular}{|lll|}
\hline Oxygen ratio & Alloy B1 & Fe \\
\hline $\mathrm{O}\left(\mathrm{H}_{2} \mathrm{O}\right) / \mathrm{O}\left(\mathrm{O}_{2}\right)$ & 1.42 & 1.51 \\
\hline
\end{tabular}

The number of oxygen atoms derived from $\mathrm{H}_{2} \mathrm{O}$ is less than the number of oxygen atoms originating from $\mathrm{O}_{2}$ for the bcc alloy compared to pure Fe. This suggests that less $\mathrm{H}_{2} \mathrm{O}$ is adsorbed for the bcc alloy material and this further supports the inference that the bcc alloy is more resistant to a $\mathrm{H}_{2} \mathrm{O}$-rich environment. It can be interpreted that surface segregation of $\mathrm{Al}$ and $\mathrm{Cr}$ plays a role for producing a more gradual stress gradient at the interface, blocking oxygen diffusion, and slowing down $\mathrm{H}_{2} \mathrm{O}$ adsorption. However, surface segregation does not occur unless a minimum initial bulk concentration of $\mathrm{Al}$ or $\mathrm{Cr}$ is met during oxidation ${ }^{33}$. 
Surface segregation of Al or $\mathrm{Cr}$ appears to be correlated with the development of a more gradual stress gradient at the metal/environment interface. The anti-corrosion properties of Fe-Cr-Al alloys strongly depend on the initial bulk concentration. Figure 4(a) shows that there is a significant amount of $\mathrm{Al}$ and a lesser amount of $\mathrm{Cr}$ segregation at the materials/environment interface when the bulk concentration is set to $\mathrm{Fe} 50 \% \mathrm{Al} 25 \% \mathrm{Cr} 25 \%$.

For Fe 75\% Al20\% Cr5\% bulk concentration, only Al segregation is observed (Fig. 4(b)). For Fe 75\% Al5\% $\mathrm{Cr} 20 \%$, neither Al nor $\mathrm{Cr}$ segregate to the interface (Fig. 4(c)). We explain this result by considering that the Al portion must be below the threshold and the $20 \% \mathrm{Cr}$ is also insufficient to cause it to segregate to the surface within the scope and timescale of our simulation. It can be concluded that a minimum portion of $\mathrm{Al}$ is required to prompt surface segregation, which leads to gradual stress gradient at the interface of oxide scale. To have $\mathrm{Cr}$ segregation, the minimum portion of $\mathrm{Cr}$ should be larger than Al.

So far, we have discussed the corrosion behavior of hypothetical Fe-Cr-Al alloy systems in a water-rich environment $\left(\mathrm{O}_{2}: \mathrm{H}_{2} \mathrm{O}=1: 3\right)$. The same kinds of simulations were conducted in an oxygen-rich environment $\left(\mathrm{O}_{2}: \mathrm{H}_{2} \mathrm{O}=3: 1\right)$ and presented in Figure $\mathrm{S} 5$ of S.I. A comparison was made for bcc, fcc alloy and pure Fe based on the three evaluation criteria (peak stress, stress gradient and summation of stress in oxide scale) under water-rich, raised temperature and oxygen rich environment in Figure S6 and Table S1 of S. I.. We found that the lower stress gradient at the alloy surface does not appear to influence the $\mathrm{O}_{2}$ adsorption and reactivity. Thus the bcc alloy is not the most corrosion resistant under these conditions. Based on our three evaluation criteria, the fcc alloy has better resistance in the early stages of corrosion than the bcc alloy under the oxygen rich environment.

\subsection{Relation of stress gradient to diffusivity of oxygen and hydrogen in the oxide scale}

Figure 5 shows the relation between stress gradient at the interface and the diffusivity of hydrogen and oxygen. As shown in Fig. 5(a) and (b), the diffusivities of $\mathrm{O}$ and $\mathrm{H}$ decrease very rapidly when they pass into the oxide scale, which is expected because (a) there is a change of state across the interface from gas, to surface adsorbate, to interstitials or other defects in the oxide and metal, and (b) it is known that stress slows down diffusivities ${ }^{34-36}$. The alloy and pure Fe have quite different diffusion profiles of the environmental species. For the alloy material, the diffusivities of $\mathrm{O}$ and $\mathrm{H}$ drop sharply for that section of the profile that has increasing stresses at the surface (the green rectangular bounding box) (Fig. 5(a)). On the contrary, in pure $\mathrm{Fe}$, the diffusivities of $\mathrm{O}$ and $\mathrm{H}$ do not decrease rapidly for the stress increasing section; $\mathrm{O}$ and $\mathrm{H}$ diffuse more rapidly inward, beyond the peak stress point. In addition, although diffusivity of $\mathrm{H}$ is higher than that of $\mathrm{O}$ for both alloy and pure $\mathrm{Fe}$, the difference between $\mathrm{H}$ and $\mathrm{O}$ diffusivity narrows for the alloy materials, whereas in pure Fe they maintain this gap in diffusivities through the oxide layer. The inset figures in Fig. 5(a) and (b) support this result, showing a mixeddisordered distribution of $\mathrm{O}$ and $\mathrm{H}$ for the alloy but a layered ordered distribution of $\mathrm{O}$ and $\mathrm{H}$ for pure Fe. To highlight distributions of oxygen and hydrogen, metal atoms are not shown in the inset figures. Due to 
the different bond lengths for $\mathrm{Al}-\mathrm{O}, \mathrm{Cr}-\mathrm{O}$ and $\mathrm{Fe}-\mathrm{O}$, this mixed-disordered distribution of oxygen is made and creates a 'self-blocking effect' of diffusion of oxygen and hydrogen as well hindering the growth of oxide scale for the alloy. On the contrary to the alloy case, for pure Fe layered $\mathrm{O}$ and $\mathrm{H}$ distributions are observed in the inset figure of Fig. 5(b) since only a single bond-type, the Fe-O bond, exists. Diffusivity of hydrogen is higher than that of oxygen, which explains the locations of oxygens and hydrogens in the oxide scale. Diffusion is dominated by interstitial diffusion.

Figures 5(c) and (d) show the diffusivity changes with time for the bcc alloy and for pure Fe, respectively. For the section of 0-0.5 ns (yellow box) in Fig. 5(c), the diffusivities do not change significantly, while a more significant decrease in diffusivities happens for the section of time from 1.5-2 ns (green box). The developing region of lower stress gradient across the emergent oxide causes the diffusivities to decrease significantly. The lower stress gradient of the alloy system contributes to lowering the diffusivities of 0 and $\mathrm{H}$. For pure Fe, the diffusivities do not decrease much for both $0-0.5 \mathrm{~ns}$ and $1.5-2 \mathrm{~ns}$ (Fig. $5(\mathrm{~d})$ ). The $\mathrm{H}$ diffusivity in pure Fe lies between $2 \times 10^{-7}$ and $5 \times 10^{-7} \mathrm{~m}^{2} / \mathrm{s}$ at the interface region, which agrees well with the experimental value ${ }^{37}$ of $2.24 \times 10^{-7} \mathrm{~m}^{2} / \mathrm{s}$. Figure $5(\mathrm{e})$ and $(\mathrm{f})$ show the diffusivity change with increasing exhaust gas pressure for the bcc alloy and for pure Fe, respectively. The lower stress gradient that occurs in the higher-pressure simulation (green box) makes the diffusivities decrease more than in the reference pressure case (yellow box) (Fig. 5(e)), while this same effect is not observed for pure Fe (Fig. 5(f)). In summary, the lower stress gradient of the alloy, resulting from the surface segregation or (alternatively) from a pressure increase, appears to play a role in decreasing the diffusivities of the oxidizing gases during corrosion processes.

\section{Conclusions}

We performed molecular dynamics simulations to investigate the high temperature corrosion behavior of metal alloys and pure Fe exposed to exhaust gases. We found that the alloying elements $\mathrm{Al}$ and $\mathrm{Cr}$ segregate to the surface during the early stages of oxidation and produce a lower stress gradient at the metal/environment interface compared to pure Fe. The reduced stress gradient slows down the rate of $\mathrm{H}_{2} \mathrm{O}$ reaction with the surface and this effect is more pronounced for the bcc alloy compared to the fcc alloy. Initially, the extremely steep stress gradient at the interface becomes shallower as time goes on for the alloy material, while the oxidation of pure Fe continues to maintain a sharp stress gradient at the metal/environment interface throughout the corrosion process. The stress gradient can also be influenced by the pressure in the environment. In addition to this, we also learned that Fe-Al-Cr ternary alloy is much better than the Fe-Al or Fe-Cr binary alloys in terms of element distribution and stress gradient at the surface: i.e. there is a synergy caused by the third element effect in these systems. Furthermore, there exist critical threshold values of the $\mathrm{Al}$ and $\mathrm{Cr}$ composition that appear to be required to take advantage of the alloy effect during the earliest stages of the oxidation process. Examination of the diffusivity profiles for $\mathrm{O}$ and $\mathrm{H}$ across the materials/environment interface shows that the elemental diffusivity drops very rapidly across the sections with a lower stress gradient. Thus, the lower stress gradient in alloyed surfaces is beneficial both mechanically and chemically, since it avoids stress

Page $11 / 20$ 
concentration and decelerates the rate of growth of the oxide scale. We compared the bcc and fcc alloys with pure Fe using the three evaluation criteria of peak stress, stress gradient and summation of stress during the corrosion process. We found that the alloys score better in these metrics compared to pure Fe. The bcc alloy appears to be the best choice under a water rich environment and the fcc alloy is proven to be the better choice under an oxygen rich environment. The surface segregation of the alloy element (Al and $\mathrm{Cr}$ ) has the effect of lowering the stress gradient. For surface segregation to occur, a minimum Al or $\mathrm{Cr}$ bulk concentration is required.

Through this study, we obtained a new insight on high temperature corrosion behaviors of metal alloy and pure Fe and provide some additional molecular level support for the underlying mechanisms of why the Al-Cr-Fe ternary system provides an excellent combination of alloying elements for high temperature oxidation resistance. The results of this study are consistent with previous experimental or DFT results not only qualitatively but also quantitatively. The favorability associated with lower stress gradients during oxidation suggests a new principle for facilitating corrosion resistant alloy design. Whereas this study only addresses the initial stages of alloy oxidation, it will be just one component of a broader multiscale model for simulating isothermal or cyclic oxidation.

\section{Declarations}

\section{ACKNOWLEDGEMENT}

This research is supported by funds from Department of Energy (DE-EE0008458).

\section{DATA AVAILABILITY}

The data that support the findings of this study are available from the corresponding authors on reasonable request.

\section{AUTHOR CONTRIBUTIONS}

S.-Y. Kim and C. T. designed the research. S.-Y. Kim performed the simulations and analyses. All authors contributed to editing the manuscript and approve of the content in its current form.

\section{COMPETING INTERESTS}

The authors declare no competing financial or non-financial interests

\section{References}

1. Taylor CD. Corrosion informatics: an integrated approach to modelling corrosion. Corrosion Engineering Science Technology. 2015;50:490-508. doi:10.1179/1743278215y.0000000012.

2. Latosov E, Maaten B, Siirde A, Konist A The influence of O-2 and $\mathrm{CO} 2$ on the possible corrosion on steel transmission lines of natural gas. International Scientific Conference Environmental and 
Climate Technologies, Conect 2018; 147, 63-70, doi:10.1016/j.egypro.2018.07.034.

3. Taylor CD, Lu P, Saal J, Frankel GS, Scully JR. Integrated computational materials engineering of corrosion resistant alloys. NPJ Mater Degrad 2, 10, 2018; doi:10.1038/s41529-018-0027-4.

4. Regina JR, DuPont JN, Marder AR. Gaseous corrosion resistance of Fe-Al-based alloys containing $\mathrm{Cr}$ additions - Part 1: Kinetic results. Mater Sci Eng A-Struct Mater Prop Microstruct Process. 2005;404:71-8. doi:10.1016/j.msea.2005.05.053.

5. Regina JR, DuPont JN, Marder AR. Gaseous corrosion resistance of Fe-Al based alloys containing $\mathrm{Cr}$ additions Part II. Scale morphology. Mater Sci Eng A-Struct Mater Prop Microstruct Process. 2005;405:102-10. doi:10.1016/j.msea.2005.05.085.

6. Wang JT, Liu SP, Bai X, Zhou XH, Han XX. Oxidation behavior of Fe-Al-Cr alloy at high temperature: Experiment and a first principle study. Vacuum 173, 9, 2020; doi:10.1016/j.vacuum.2019.109144.

7. Nurmi E, Wang G, Kokko K, Vitos L. Assessing the elastic properties and ductility of Fe-Cr-Al alloys from ab initio calculations. Philos Mag. 2016;96:122-33. doi:10.1080/14786435.2015.1119906.

8. Liu S, Shen J, Guo XH, Liu LL, Niu Y. Corrosion of Fe-Ni-Cr alloys with various aluminum additions in a carburizing-oxidizing atmosphere at 900 degrees C. Corrosion Sci. 2018;135:67-77. doi:10.1016/j.corsci.2018.02.024.

9. Airiskallio E, et al. High temperature oxidation of Fe-Al and Fe-Cr-Al alloys: The role of $\mathrm{Cr}$ as a chemically active element. Corrosion Sci. 2010;52:3394-404. doi:10.1016/j.corsci.2010.06.019.

10. Chen HZ, Li BR, Wen B, Ye Q, Zhang NQ. Corrosion resistance of iron-chromium-aluminium steel in eutectic molten salts under thermal cycling conditions. Corrosion Sci. 2020;173:16. doi:10.1016/j.corsci.2020.108798.

11. Hirata K, likubo S, Koyama M, Tsuzaki K, Ohtani H, FCC, and Iron HCP. First-Principles Study on Hydrogen Diffusivity in BCC. Metall Mater Trans A-Phys Metall Mater Sci. 2018;49A:5015-22. doi:10.1007/s11661-018-4815-9.

12. Sankaranarayanan S, Ramanathan S. On the Low-Temperature Oxidation and Ultrathin Oxide Growth on Zirconium in the Presence of Atomic Oxygen: A Modeling Study. J Phys Chem C. 2008;112:17877-82. doi:10.1021/jp804872u.

13. Campbell TJ, et al. Oxidation of aluminum nanoclusters. Phys Rev B 71, 14, 2005; doi:10.1103/PhysRevB.71.205413.

14. Subbaraman R, Deshmukh SA, Sankaranarayanan S. Atomistic Insights into Early Stage Oxidation and Nanoscale Oxide Growth on Fe(100), Fe(111) and Fe(110) Surfaces. J Phys Chem C. 2013;117:5195-207. doi:10.1021/jp312514m.

15. Fensin SJ, et al. Structural disjoining potential for grain-boundary premelting and grain coalescence from molecular-dynamics simulations. Phys Rev E 81, 10, 2010; doi:10.1103/PhysRevE.81.031601.

16. Das NK, Suzuki K, Takeda Y, Ogawa K, Shoji T. Quantum chemical molecular dynamics study of stress corrosion cracking behavior for fcc Fe and Fe-Cr surfaces. Corrosion Sci. 2008;50:1701-6. doi:10.1016/j.corsci.2008.01.032. 
17. Deshmukh SA, Sankaranarayanan S. Atomic scale characterization of interfacial water near an oxide surface using molecular dynamics simulations (vol 14, pg 15593, 2012). Phys Chem Chem Phys. 2012;14:16794-4.

18. Rustad JR, Hay BP, Halley JW, MOLECULAR-DYNAMICS, SIMULATION. OF IRON(III) AND ITS HYDROLYSIS PRODUCTS IN AQUEOUS-SOLUTION. J Chem Phys. 1995;102:427-31. doi:10.1063/1.469419.

19. van Duin ACT, Dasgupta S, Lorant F, Goddard WA. ReaxFF: A reactive force field for hydrocarbons. J Phys Chem A. 2001;105:9396-409. doi:10.1021/jp004368u.

20. Shin YK, Kwak H, Vasenkov AV, Sengupta D, van Duin ACT. Development of a ReaxFF Reactive Force Field for $\mathrm{Fe} / \mathrm{Cr} / \mathrm{O} / \mathrm{S}$ and Application to Oxidation of Butane over a Pyrite-Covered $\mathrm{Cr} 2 \mathrm{O} 3$ Catalyst. ACS Catal. 2015;5:7226-36. doi:10.1021/acscatal.5b01766.

21. Plimpton S, FAST PARALLEL ALGORITHMS FOR SHORT-RANGE, MOLECULAR-DYNAMICS. J Comput Phys. 1995;117:1-19. doi:10.1006/jcph.1995.1039.

22. Lekakh SN, et al. High Temperature Oxidation and Decarburization of SiMo Cast Iron in Air and Combustion Atmospheres. Oxidation of Metals, 18, doi:10.1007/s11085-021-10022-1.

23. Aktulga F, Pandit \& Grama. Parallel Computing, 2012; 245-249.

24. Mortier WJ, Ghosh SK, Shankar S, ELECTRONEGATIVITY EQUALIZATION METHOD FOR, THE CALCULATION OF ATOMIC CHARGES IN MOLECULES. J Am Chem Soc. 1986;108:4315-20. doi:10.1021/ja00275a013.

25. van Duin ACT, Larter SR. Molecular dynamics investigation into the adsorption of organic compounds on kaolinite surfaces. Org Geochem. 2001;32:143-50. doi:10.1016/s01466380(00)00143-1.

26. Chenoweth K, van Duin ACT, Goddard WA. ReaxFF reactive force field for molecular dynamics simulations of hydrocarbon oxidation. J Phys Chem A. 2008;112:1040-53. doi:10.1021/jp709896w.

27. From. the website https://en.wikipedia.org/wiki/Von_Mises_yield_criterion.

28. Sarin P, Snoeyink VL, Lytle DA, Kriven WM. Iron corrosion scales: Model for scale growth, iron release, and colored water formation. J Environ Eng. 2004;130:364-73. doi:10.1061/(asce)07339372(2004)130:4(364).

29. Opila EJ, Jacobson NS, Myers DL, Copland EH. Predicting oxide stability in high-temperature water vapor. Jom. 2006;58:22-8. doi:10.1007/s11837-006-0063-3.

30. Ryabukhin AG, Roshin VE, Roshin AV. Calculation of the Effective lonic Radii of Al1 + and Al2+, the Standard Enthalpies of Formation of the Crystalline Oxides Al2O, AlO, and Al304, and the Enthalpies of Their Crystal Lattices. Russ Metall, 98-104, 2007; doi:10.1134/s0036029507020024.

31. Kim SY, et al. Self-generated concentration and modulus gradient coating design to protect Si nanowire electrodes during lithiation. Phys Chem Chem Phys. 2016;18:3706-15. doi:10.1039/c5cp07219k. 
32. Klein MCG, Gorb SN. Epidermis architecture and material properties of the skin of four snake species. J R Soc Interface. 2012;9:3140-55. doi:10.1098/rsif.2012.0479.

33. Idczak K, Idczak R. Investigation of Surface Segregation in Fe-Cr-Si Alloys by XPS. Metall Mater Trans A-Phys Metall Mater Sci. 2020;51:3076-89. doi:10.1007/s11661-020-05758-5.

34. Dong XL, Fang XF, Feng X, Hwang KC. Diffusion and Stress Coupling Effect during Oxidation at High Temperature. J Am Ceram Soc. 2013;96:44-6. doi:10.1111/jace.12105.

35. Yue MK, Dong XL, Fang XF, Feng X. Effect of interface reaction and diffusion on stress-oxidation coupling at high temperature. J Appl Phys 123, 6, 2018; doi:10.1063/1.5025149.

36. Dong XL, Fang XF, Feng X, Sun XY. Oxidation at High Temperature Under Three-Point Bending Considering Stress-Diffusion Coupling Effects. Oxid Met. 2016;86:125-33. doi:10.1007/s11085-0169626-z.

37. Hagi H, Hayashi Y, Ohtani N, DIFFUSION-COEFFICIENT OF HYDROGEN IN, PURE IRON BETWEEN 230K AND 300-K. Transactions of the Japan Institute of Metals. 1979;20:349-57. doi:10.2320/matertrans1960.20.349.

\section{Figures}
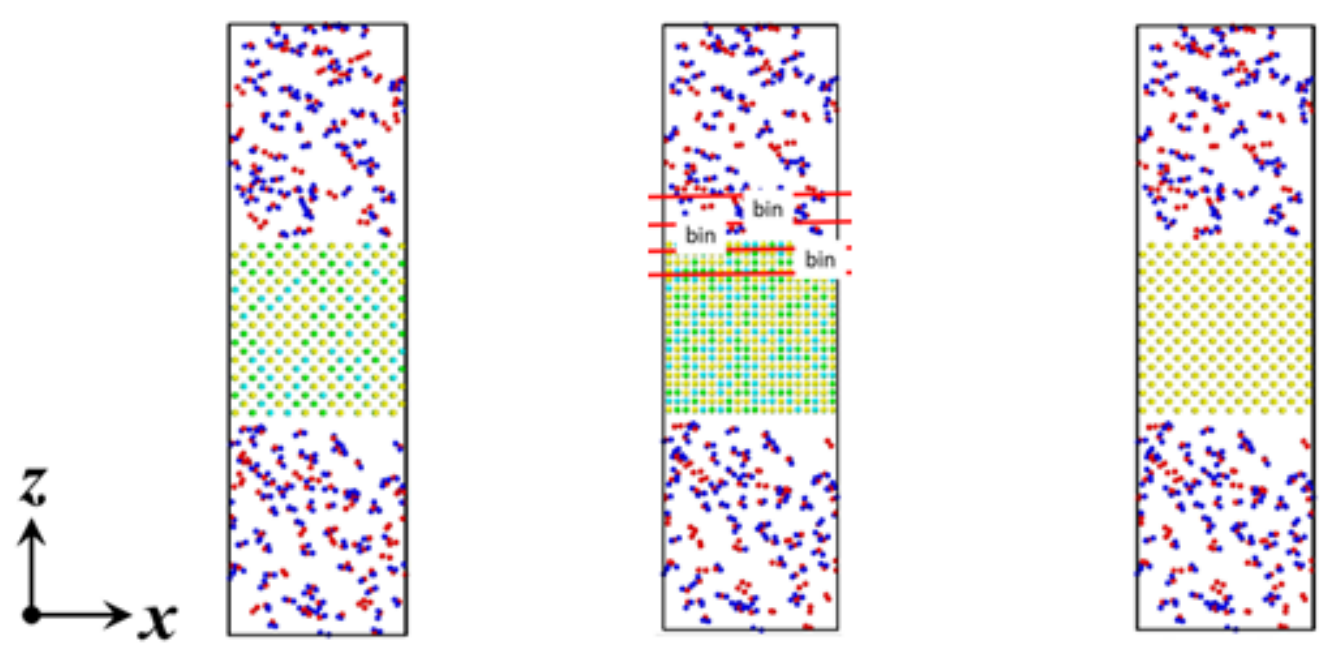

Figure 1

Initial configuration of simulation set for (a)bcc alloy, (b)fcc alloy and (c)Fe (bcc) (Al:green, Cr:cyan, Fe:yellow, O:red and $\mathrm{H}$ :blue). For the alloy composition, 1) $50 \% \mathrm{Fe} ; 25 \% \mathrm{Al} ; 25 \% \mathrm{Cr}$, 2) $70 \% \mathrm{Fe} ; 25 \% \mathrm{Al} ; 5 \%$ $\mathrm{Cr}$, and 3) $70 \% \mathrm{Fe} ; 25 \% \mathrm{Cr}$; $5 \%$ Al were used. Table I shows alloy notations, the atomic percent of the elements in the alloy and the corresponding weight percent used in this study. 


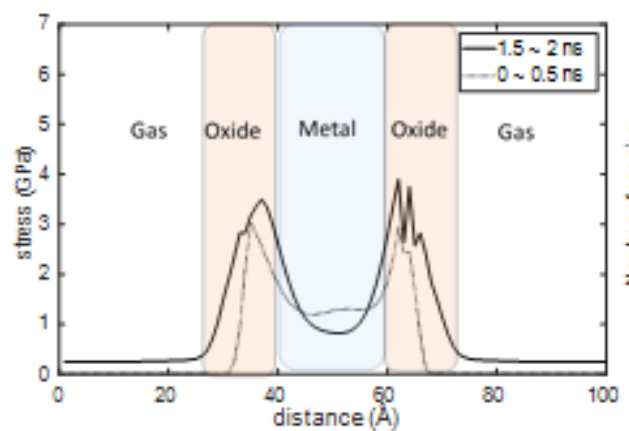

(a) Alloy B1

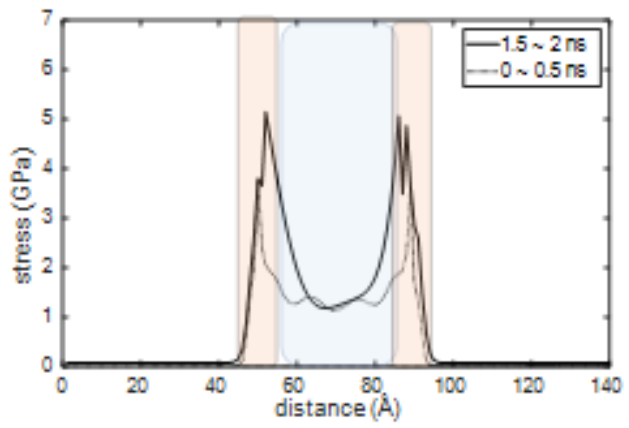

(b) Alloy F1

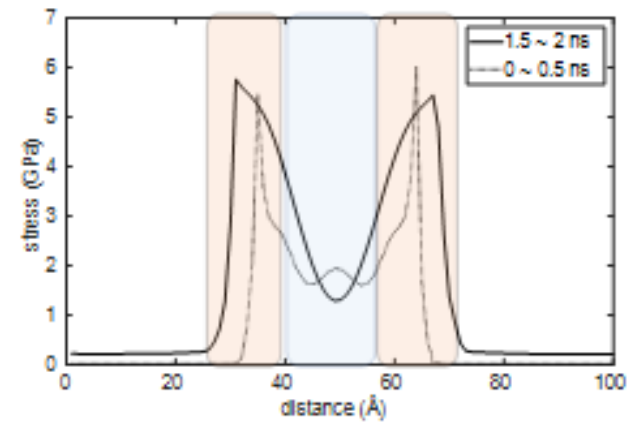

(c) $\mathrm{Fe}$

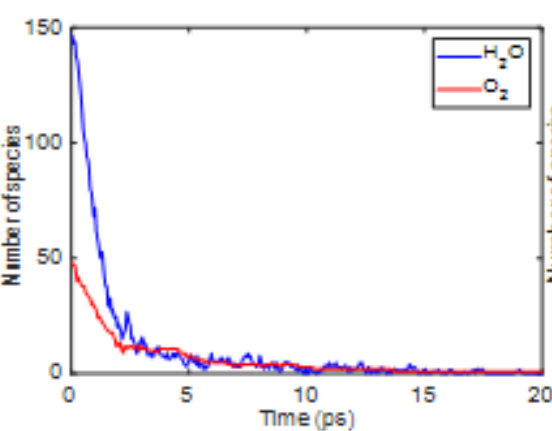

(d) Alloy B1 (0 $20 \mathrm{ps})$

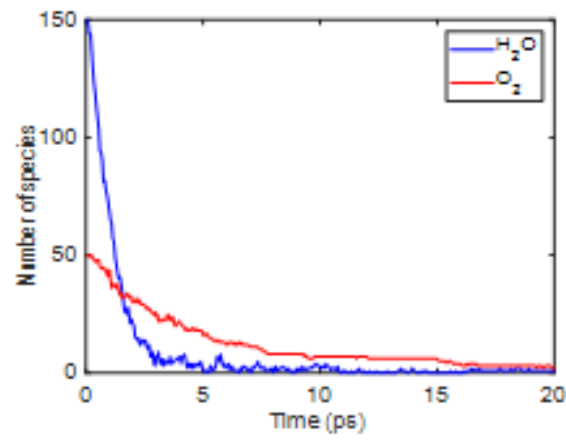

(e) Alloy F1 (0 $20 \mathrm{ps})$

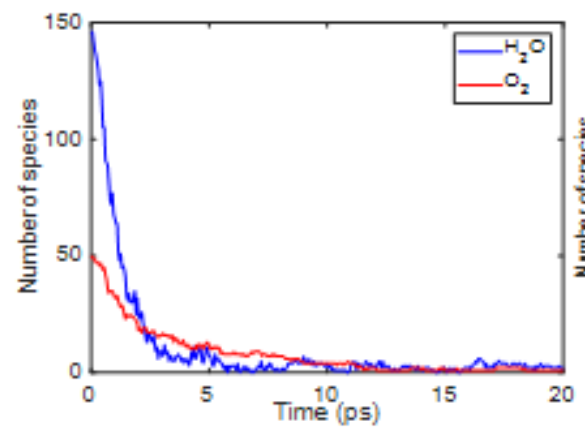

(f) $\mathrm{Fe}(0 \sim 20 \mathrm{ps})$

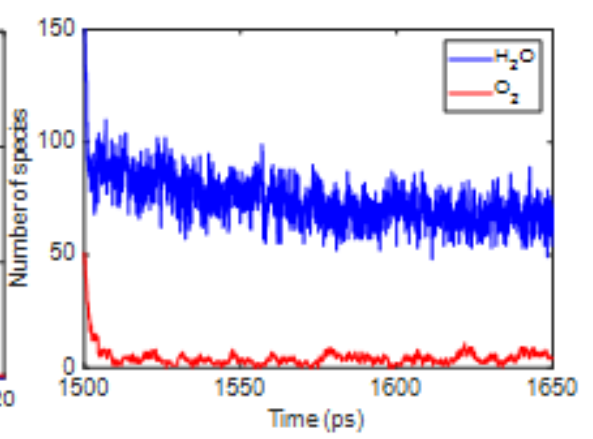

(g) Alloy B1 (1.5 1.65ns)

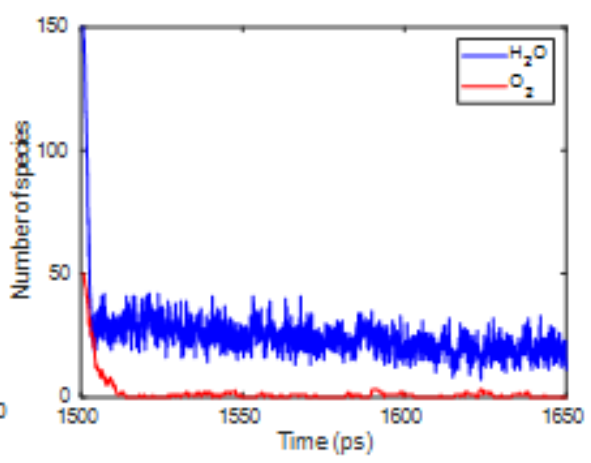

(h) Alloy F1 (1.5 1.65ns)

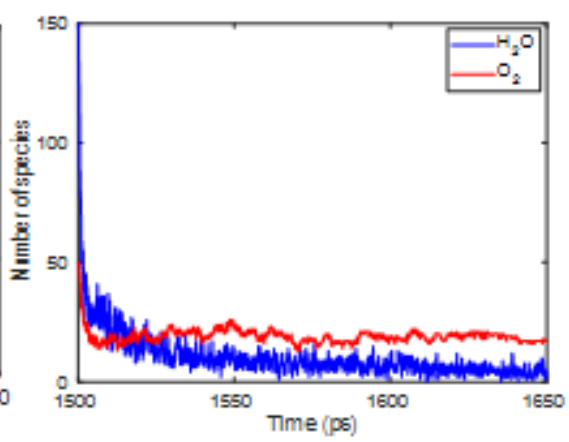

(i) Fe $(1.5 \sim 1.65 \mathrm{~ns})$

\section{Figure 2}

Temporal variations of mean stress profiles from pre-oxidation ( $0 \sim 0.5 \mathrm{~ns})$ to early stage oxide film formation (1.5 2.0 ns) for (a)bcc, (b)fcc alloys and (c)pure Fe. Each alloy near-surface region is set to $50 \% \mathrm{Fe}, 25 \% \mathrm{Al}$ and $25 \% \mathrm{Cr}$ in the initial condition (Table I) and the orientation of all structures is the (100) surface. $\mathrm{H} 2 \mathrm{O}$ and $\mathrm{O} 2$ adsorption and reaction on alloy surfaces are monitored pre-oxidation and then after the formation of the initial oxide film on alloy surfaces compared to pure iron. The evolution of the number of free $\mathrm{H} 2 \mathrm{O}$ and $\mathrm{O} 2$ molecules in the simulation cells with time is shown for (d)Alloy $\mathrm{B} 1$ ( 0 20 ps), (e) Alloy F1(0 20 ps), (f)pure Fe (0 20 ps), (g)Alloy B1(1.5 1.65 ns), (h)Alloy F1(1.5 1.65 $\mathrm{ns})$ and (i)pure $\mathrm{Fe}(1.5 \sim 1.65 \mathrm{~ns})$, respectively. The exhaust gases consist of $\mathrm{O} 2$ and $\mathrm{H} 2 \mathrm{O}(\mathrm{O} 2: \mathrm{H} 2 \mathrm{O}=1: 3)$. The temperature is $800 \mathrm{~K}(527 \mathrm{oC})$, i.e. the lower bound on exhaust gas temperatures. 


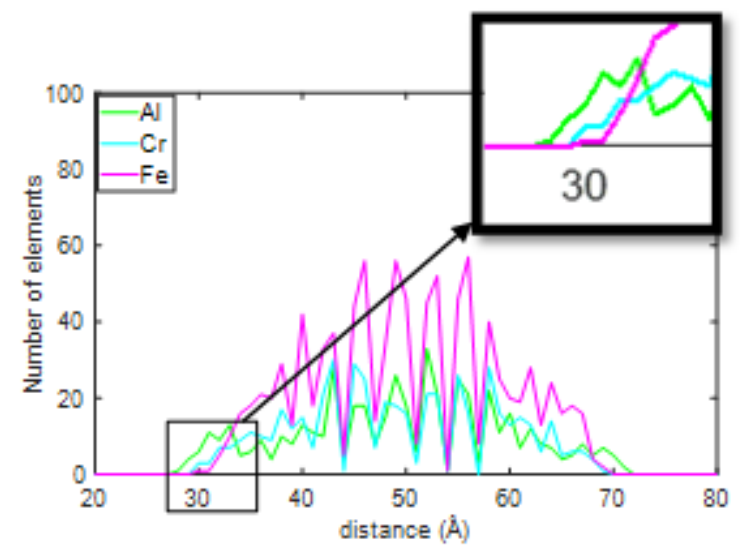

(a)

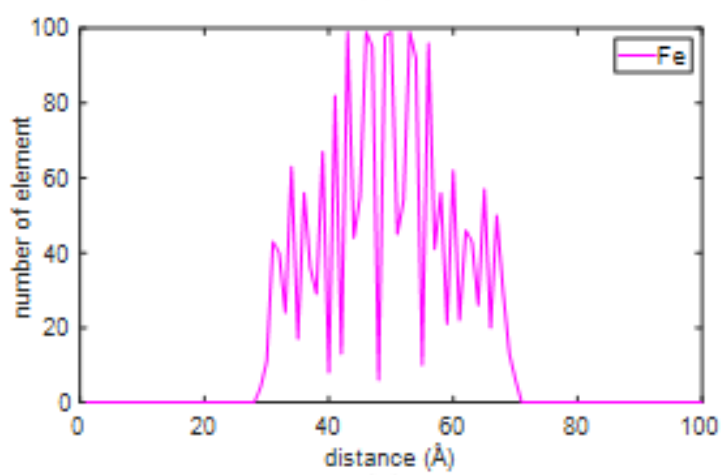

(c)

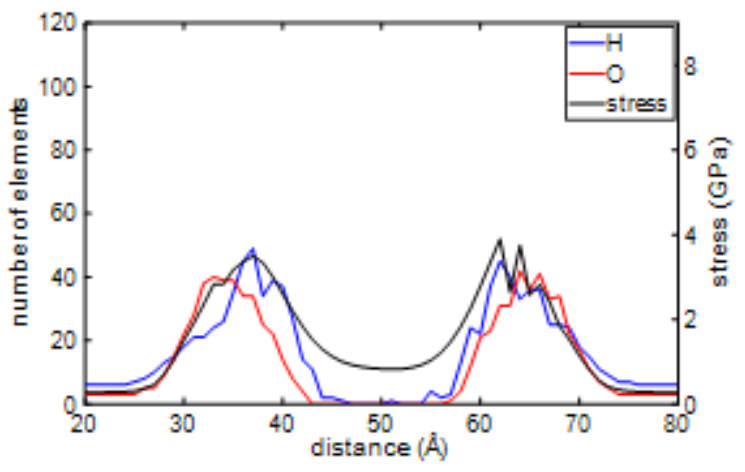

(b)

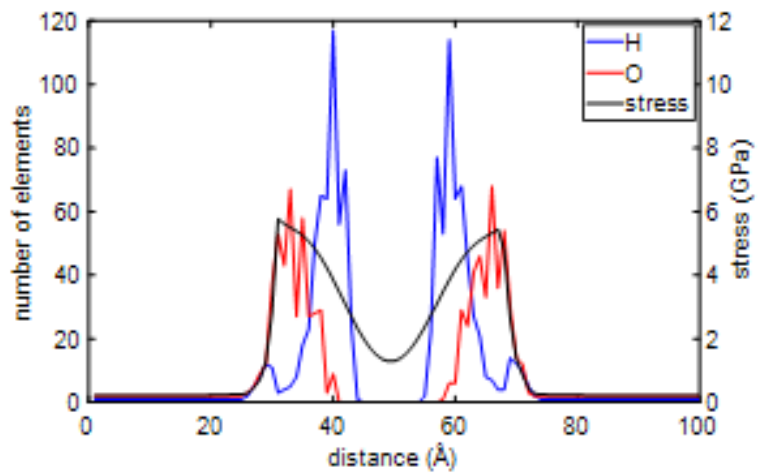

(d)

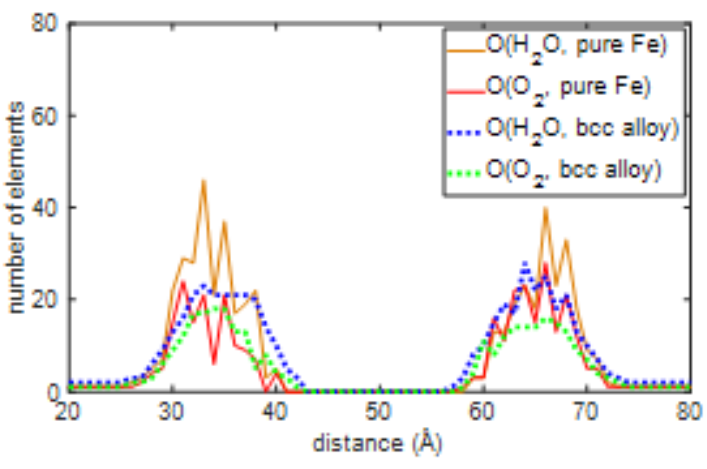

(e)

\section{Figure 3}

(a) Elemental (Al, Cr and Fe) distributions of bcc alloy (Alloy B1) during oxidation (1.5 -2 ns) (b) Hydrogen, oxygen distribution and stress profile relationship for bcc alloy (Alloy B1) (c) Fe distribution of pure Fe during oxidation (1.5 - 2ns) (d) Hydrogen, oxygen distribution and stress profile relationship for pure Fe (e) Oxygen distribution in bcc alloy (Alloy B1) and pure Fe. (O2: H2O=1:3, 800K) 


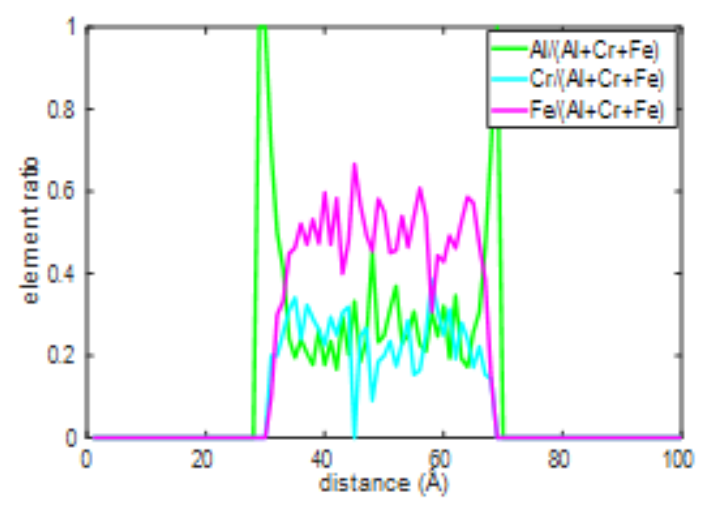

(a) $\mathrm{Fe} 50 \%$ Al25\% Cr25\% (Alloy B1)

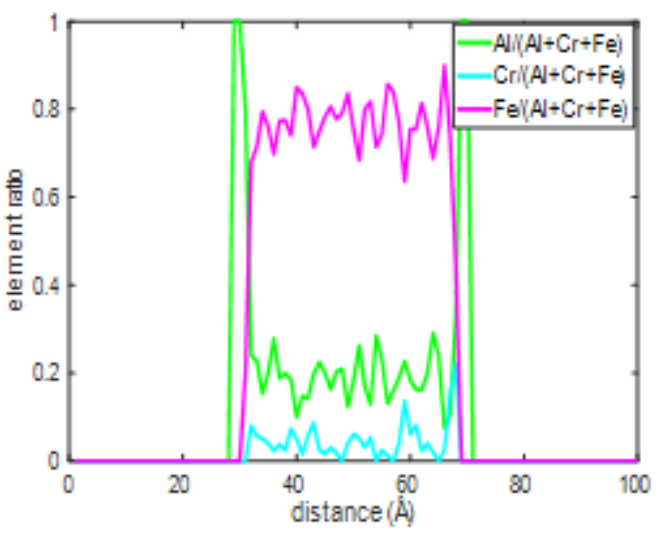

(b) $\mathrm{Fe} 75 \% \mathrm{Al} 20 \% \mathrm{Cr} 5 \%$ (Alloy B2)

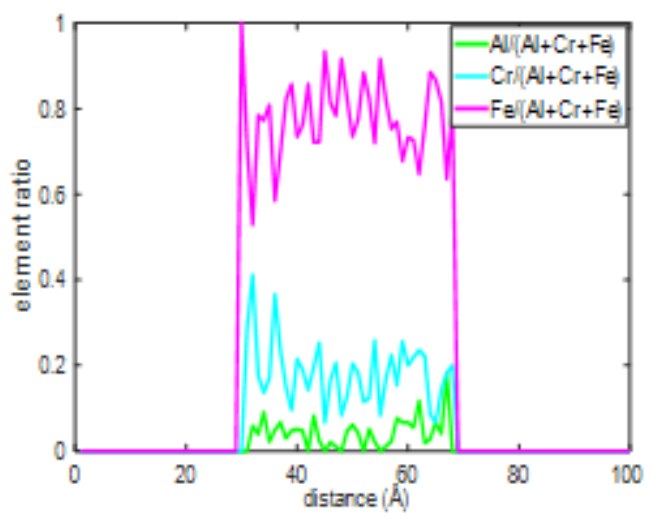

(c) Fe75\% Al5\% Cr20\% (Alloy B3)

\section{Figure 4}

Surface segregation effect depending on initial bulk concentration of $\mathrm{Al}$ and $\mathrm{Cr}$ during oxidation. (1.0 -1 $.5 \mathrm{~ns}, 800 \mathrm{~K})$ 


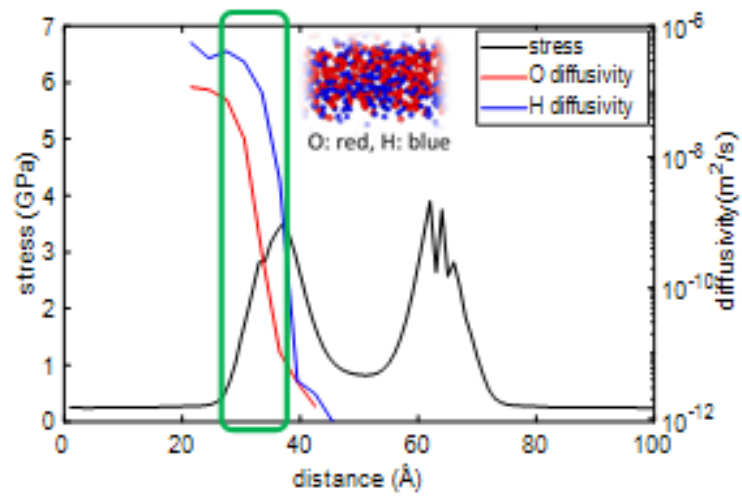

(a) Stress profile and diffusivity for Alloy B1 (1.5 - 2 ns)

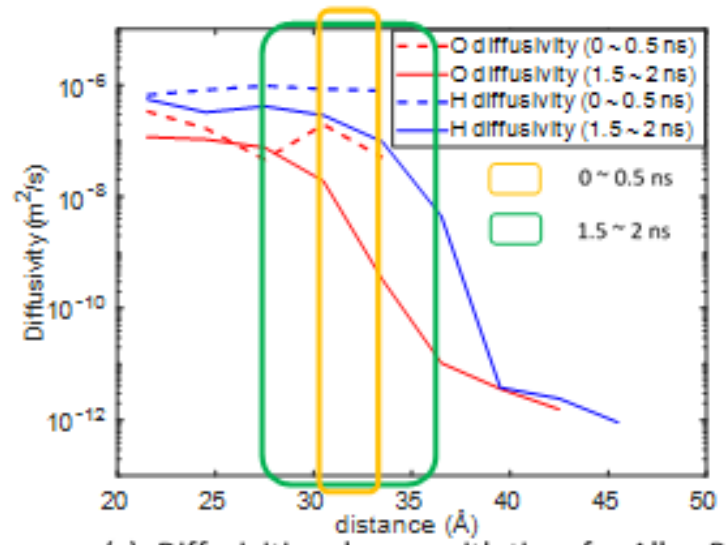

(c) Diffusivities change with time for Alloy B1

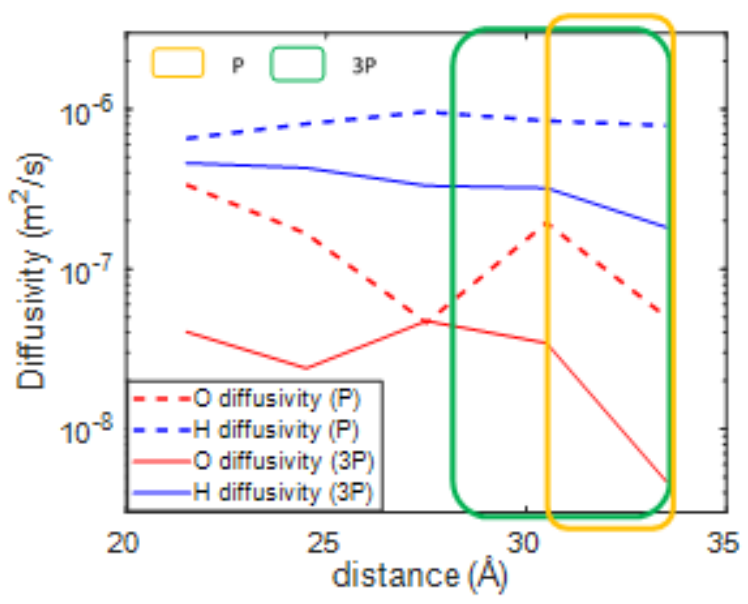

(e) Diffusivities change with pressure for Alloy B1

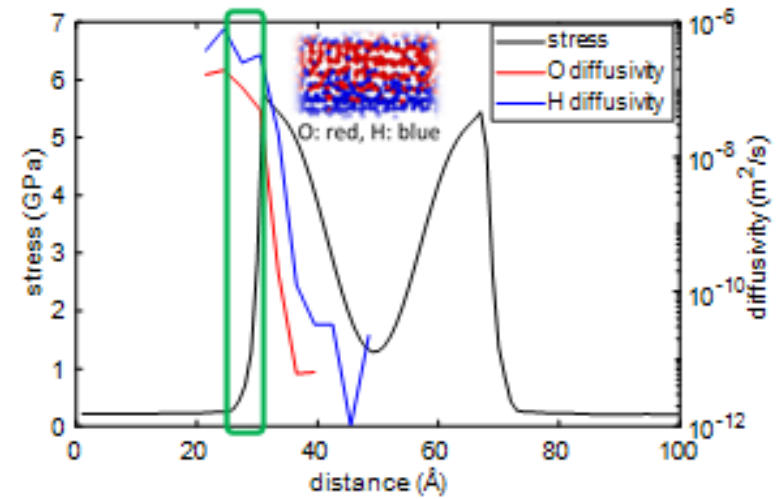

(b) Stress profile and diffusivity for Fe (1.5 - $2 \mathrm{~ns}$ )

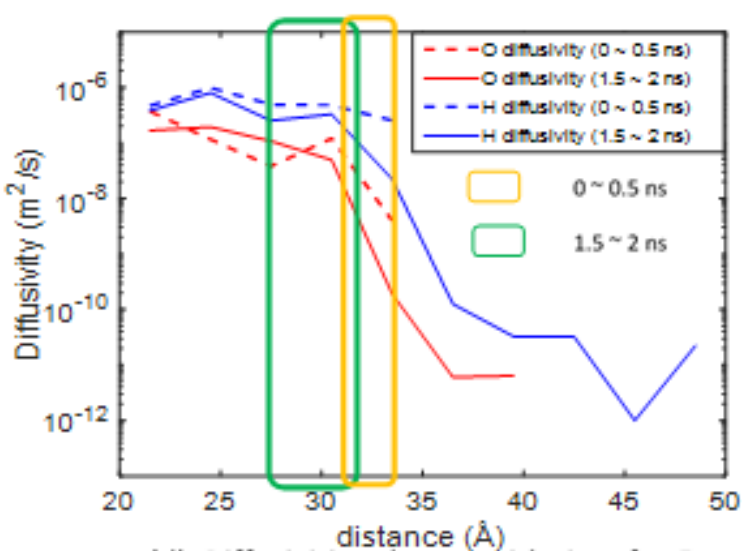

(d) Diffusivities change with time for Fe

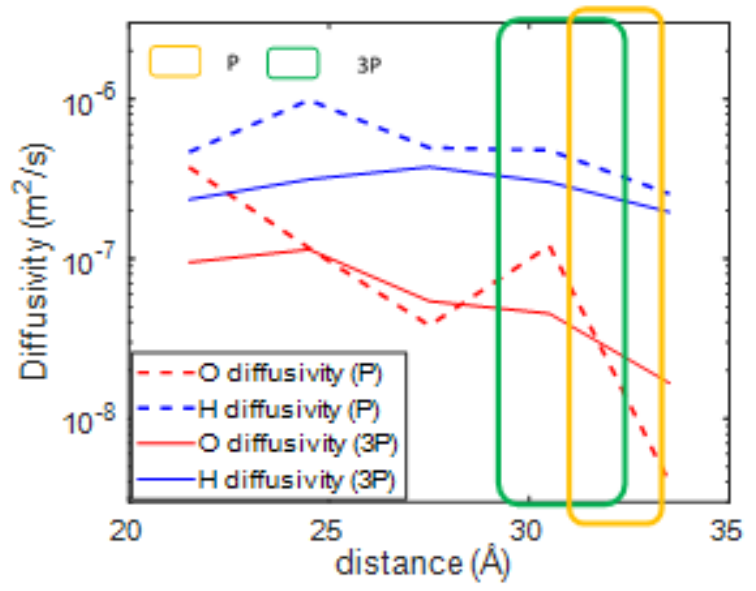

(f) Diffusivities change with pressure for Fe

\section{Figure 5}

Effect of stress on the diffusivity of Hydrogen and Oxygen. (a) Stress profile and diffusivity for bcc alloy (Alloy B1) (b) stress profile and diffusivity for pure Fe (c)diffusivity change with time for bcc alloy (Alloy B1), (d) diffusivity change with time for pure Fe, (e) diffusivity change with pressure for bcc alloy and (f) diffusivity change with pressure for pure Fe. Sections having increasing stress at the surface are highlighted by the rectangular bounding box.

\section{Supplementary Files}


This is a list of supplementary files associated with this preprint. Click to download.

- SupportingInformation12July21.docx 